\title{
Ações retrospectivas e prospectivas na elaboração de materiais didáticos para educação a distância: Perfo_List como proposição metodológica
}

\author{
Elena Maria Mallmann \\ MEN/CED/UFSC \\ elena@ead.ufsc.br
}

\begin{abstract}
Resumo
As questões teórico-metodológicas do processo de elaboração de materiais didáticos para mediação pedagógica em Educação a Distância podem ser potencializadas se forem contempladas etapas retrospectivas e prospectivas de ação, avaliação e replanejamentos. Este trabalho é parte de uma investigação sobre a performance de professores-autores e designers de mediação no processo de elaboração de materiais didáticos impressos e hipermidiáticos para um curso de licenciatura. A metodologia utilizada segue os princípios da espiral cíclica ascendente da investigação-ação. $O$ Perfo_List é um formulário de indicadores organizado no modo checklist resultante da investigação sobre a performance de professores-autores e designers de mediação numa equipe multidisciplinar atuante. O Perfo_List é uma proposição metodológica que auxilia na gestão de equipes multidisciplinares, como ferramenta de avaliação e diagnóstico (retrospecção), bem como investimento em estratégias de capacitação e apoio logístico (prospecção).
\end{abstract}

Palavras-chave: Educação a Distância, Designer de Mediação, Material Didático.

\section{Shares retrospective and prospective in the development of teaching materials for distance education: Perfo_List as proposing methodological}

\begin{abstract}
The theoretical and methodological issues in the process of (re) development of educational materials for mediation in distance learning can be enhanced if steps are contemplated retrospective and prospects for action, evaluation and rescheduled. This work is part of a survey which investigated the performance of teachers, authors and designers of mediation in the process of (re) development of teaching materials printed and hipermidiatic for a course of graduate. The methodology used follows the principles of momentum in cyclical upward spiral of research-action. The Perfo_List is a form of indicators organized in order checklist resulting from the investigation on the performance of teachers, authors and designers to mediate a multidisciplinary team working. The Perfo_List is proposing a methodology that helps the management of multidisciplinary teams, as a tool for assessment and diagnosis (retrospection), as well as strategies for investment in training and logistical support (exploration).
\end{abstract}

Key_words: Distance Education, Instructional Design, Didactic Material 


\section{Mediação pedagógica em EaD: foco na elaboração de materiais didáticos}

A mediação pedagógica em $\mathrm{EaD}$ se constitui pelas situações de ensinoaprendizagem organizadas em torno dos materiais didáticos enquanto elementos que sustentam as interações síncronas e assíncronas entre professores, tutores e estudantes. "Além dos saberes a ensinar, o processo ensino-aprendizagem se constitui fundamentalmente na relação que as pessoas estabelecem com o conhecimento num quadro espaço-temporal educacional. Nessa relação já não se pode priorizar apenas o professor ou os estudantes ou o conteúdo escolar, ou seja, ou os mediadores humanos ou os não-humanos" (Mallmann, 2008, p.80).

$\mathrm{Na}$ mediação pedagógica em $\mathrm{EaD}$, a referência aos materiais didáticos é um componente muito importante porque eles orientam o processo ensino-aprendizagem. As políticas públicas, voltadas para melhoria da qualidade do ensino em todos os níveis, têm se ocupado cada vez mais com critérios de avaliação e disponibilização dos recursos. Em EaD essas políticas vêm incentivando, especialmente os professores universitários, a elaborarem materiais didáticos para as disciplinas sob sua responsabilidade. Nesse sentido, os mediadores não-humanos (Latour,1999; 2001), que são os materiais didáticos impressos e hipermidiáticos, assumem cada vez mais espaço.

Desse modo, o papel de professores-autores e designers de mediação (mais conhecidos como designers instrucionais) numa equipe multidisciplinar composta por profissionais oriundos da área de conhecimento específico, pedagogia, tecnologia, design, línguas, gestores e especialistas em $\mathrm{EaD}$ precisam ser constantemente avaliados em cada uma das etapas de elaboração. A multidisciplinaridade característica da equipe diz respeito à interferência de cada um nos materiais impressos e hipermidiáticos efetivamente desenvolvidos. As preocupações ampliam-se para além da abordagem dos conteúdos propriamente ditos estendendo-se para os componentes da sua organização didático-metodológica.

Além dos professores-autores, responsáveis em primeira instância pelos conteúdos curriculares de cada curso (organização conceitual e temas estruturadores), os outros profissionais que integram a equipe multidisciplinar atuam no planejamento didático-metodológico dos materiais impressos e hipermidiáticos, na customização dos ambientes virtuais, desenvolvimento de ilustrações, animações, simulações, diagramação, sistemas de acompanhamento e tutoria. (Filatro, 2004; Isman, 2005; Juuti, 2005; Vargas, 2007).

Professores-autores e designers de mediação precisam ampliar os saberes de referência, atender as orientações curriculares oficiais e ter conhecimento científicotecnológico. Na mesma perspectiva, seu conhecimento pedagógico é imprescindível para atingir a coerência das escolhas teórico-metodológicas e os princípios estruturantes do projeto pedagógico. A contribuição com os objetivos do nível de ensino, com o pensamento autônomo e as funcionalidades da vida prática é um grande desafio para os autores de materiais didáticos. $\mathrm{O}$ respeito à diversidade sócio-cultural acentuado na população-alvo específica de $\mathrm{EaD}$ implica num compromisso ético e na adequação conceitual como fatores condicionantes da transposição didática. Além da organização conceitual, aspectos como orientações pertinentes para realização de atividades de aprendizagem e o estabelecimento dos critérios de avaliação são demandas que precisam ser contempladas nos materiais.

A questão central é de que modo garantir o processo de trabalho cooperativo, competente, autônomo e ético nas equipes multidisciplinares diante dessa diversidade de aspectos que implicam reconfigurações nos modelos logísticos nas instituições, de infra-estrutura tecnológica e especificidade pedagógica. 
Desenvolveu-se uma investigação com o foco analítico voltado para performance docente (professores-autores e designers de mediação) na instância produtiva do processo de elaboração de materiais didáticos em equipe multidisciplinar. $\mathrm{Ou}$ seja, o envolvimento efetivo como designers de mediação numa equipe multidisciplinar permitiu investigar as singularidades das questões teóricometodológicas que giram em torno do processo de elaboração de materiais didáticos para EaD. Conceitualmente optou-se pelo termo "performance" ao invés de desempenho, uma vez que o primeiro é tecido a partir da linguagem artística carregando um sentido mais próximo de termos como criação, ação e autoria (Mallmann, 2008).

A elaboração de materiais didáticos é uma situação inédita no contexto da docência universitária, uma vez que, do ponto de vista dos envolvidos, poucos possuem experiência com a modalidade a distância, com um processo de elaboração de materiais didáticos, trabalhos cooperativos em equipes multidisciplinares e inserção das tecnologias digitais de informação e comunicação na mediação pedagógica. A inovação na docência universitária a partir do envolvimento no processo de elaboração de materiais didáticos para $\mathrm{EaD}$ está explicitada em aspectos como: rigorosidade conceitual na área específica; necessidade de conhecer o projeto pedagógico do curso para contemplar uma unidade teórico-metodológica nos materiais da disciplina no curso; compreender a importância dos elementos constitutivos de um texto para modalidade a distância (objetivos, glossários, links, referências, complementos, exemplos, agendas, calendários, atividades, exercícios, avaliações periódicas); organizar os materiais numa linguagem mais dialógica tendo em vista o público-alvo; propor estratégias que impliquem princípios como autonomia, interação e cooperação dos estudantes e garantir a interação nas atividades síncronas e assíncronas.

O desenvolvimento de material didático para $\mathrm{EaD}$ incorpora a criação de novas subjetividades porque requer não mais uma performance docente de reprodução de livros didáticos, mas autoria e co-autoria. Isso é inédito para muitos professores, além de todas as outras especificidades institucionais que a modalidade a distância abarca. Sendo inédito, interfere nos modos de ser, pensar e agir docentes no interior das próprias equipes requerendo, assim, uma sistemática de avaliação e replanejamento periódico na perspectiva de diagnosticar as situações-limite e propor novas soluções a curto ou médio prazo.

Devido às nuances de um processo de elaboração de materiais didáticos para EaD numa equipe multidisciplinar é imprescindível compreender as particularidades do seu próprio processo de gestão. Há uma diversidade de definições e caracterizações sobre gestão e devido à sua complexidade, de modo geral, se confunde com gerência. Porém, neste trabalho se resgata a gestão como um processo explicitado nos planejamentos, decisões e ações retrospectivas e prospectivas dos envolvidos. $\mathrm{O}$ processo de gestão de uma equipe multidisciplinar se situa como uma dinâmica de análise e reflexão dado o contexto específico da mediação pedagógica em $\mathrm{EaD}$, num plano que envolve mais intensamente princípios de comunicação, autonomia, interação e cooperação.(Mallmann e Catapan, 2007).

Conforme Rumble (2003) "a gestão é o processo que permite conduzir, com apoio do pessoal envolvido, uma atividade com eficiência e eficácia. A gestão é um exercício comum a todas as organizações, quer tenham finalidade lucrativa ou não. $\mathrm{O}$ ensino não é uma exceção. É fundamental, para os diferentes atores do processo que a gestão do ensino seja eficiente e eficaz" (p.13). Os apontamentos do autor fortalecem a questão-chave na análise sobre a necessidade do desenvolvimento de estratégias que envolvam dinâmicas retrospectivas e prospectivas na gestão nos processos de ensino- 
aprendizagem (nesse caso, tratando-se de um processo vinculado à EaD) tendo em vista o envolvimento de diferentes profissionais.

Dessa forma, a gestão de uma equipe multidisciplinar requer um modo de organização complexo que se define ao longo do processo orientado teóricometodologicamente pelos princípios de democratização, participação, autonomia e, principalmente, da comunicação. Nessa perspectiva, o desenvolvimento de métodos e tecnologias que possam auxiliar nessa sistematização é emergente. Ainda mais, levando-se em consideração que a EaD está em processo de expansão devido ao aumento da oferta de cursos de graduação, pós-graduação e educação profissional técnica. Cada vez mais os professores estão se envolvendo com o planejamento e implementação de cursos nessa modalidade.

\section{Perfo_List como proposição metodológica}

O processo de elaboração de materiais didáticos impressos e hipermidiáticos para $\mathrm{EaD}$ envolve diversos profissionais com destaque para os professores-autores e designers de mediação. O trabalho do Designer de Mediação (Mallmann, 2008) em equipes multidisciplinares possui desafios em cada uma das etapas de planejamento, preparação e implementação de projetos em EaD, pois exige um alto nível de comprometimento e formação dos profissionais envolvidos como vem sendo enfatizado em textos que abordam a retrospectiva histórica do trabalho do profissional conhecido como Designer Instrucional (Romiszowski e Romiszowski, 2005).

Existem também os coordenadores e gestores que tem a função de promover a integração entre os profissionais, cuidar das condições logísticas e espaço-temporais de trabalho. Tudo isso para garantir comprometimento ético com o processo, satisfação, auto-estima, compartilhamento das informações, situações dialógicas e cooperativas, inovações didático-metodológicas e tecnológicas, bem como atenção às especificidades conceituais da área, da modalidade e do projeto pedagógico por cada um dos componentes da equipe de trabalho.

Na literatura sobre EaD, Rumble (2003) é um autor que discute as implicações e a importância da gestão. Para ele, os gestores "dirigirem o trabalho dos outros. São responsáveis por pelo menos quatro funções: planejamento, organização, direção e controle" (p.16). Nesse sentido, é imprescindível que em EaD se desenvolvam métodos e tecnologias que possam contemplar as especificidades do processo de elaboração dos materiais didáticos, especialmente das interferências dos profissionais envolvidos na equipe multidisciplinar.

As quatro funções destacadas pelo autor implicam nas etapas retrospectivas de avaliação de um processo em movimento, bem como sistematização de ações prospectivas que possam reorganizar o fluxo produtivo na direção desejada em virtude dos prazos, dos financiamentos, das condições de infra-estrutura, prioridades conceituais, competências dos profissionais envolvidos e das necessidades do públicoalvo. Desse modo, a otimização da gestão das equipes multidisciplinares de desenvolvimento de materiais didáticos para $\mathrm{EaD}$ está associada à criação de métodos e tecnologias que contemplem etapas retrospectivas e prospectivas de ação, avaliação e replanejamentos próprias da dinâmica em espiral ascendente preconizada pela investigação-ação.

A potencialidade dos materiais didáticos para mediação pedagógica em $\mathrm{EaD}$ resulta das competências singulares de cada um dos profissionais envolvidos na equipe multidisciplinar, especialmente dos professores-autores e dos designers de mediação. A 
fluidez de uma proposta para modalidade a distância depende da atuação criteriosa e ao mesmo tempo dinâmica de quem assume o processo de gestão do todo projeto e também das equipes em particular. O desafio está em garantir a coerência interna entre o que está no planejamento do curso e aquilo que é produzido e implementado.

O material didático enquanto produto de um processo de elaboração coletiva, uma vez que envolve uma equipe de trabalho multidisciplinar, reflete, explícita ou implicitamente, os modos de organização e articulação do processo produtivo. Para isso, o critério mínimo para unidade teórico-metodológica é o estabelecimento de canais de diálogo e sistematização, principalmente entre professores-autores e designers de mediação. O diálogo em torno de um problema a resolver, nesse caso focalizado na produção de material didático para EaD, pode gerar situações cooperativas, autônomas, ou seja, mais sensíveis para as demandas de aprendizagem. Para que o processo de desenvolvimento dos materiais didáticos consiga ser pensado coletivamente é necessário compartilhamento de decisões e resultados. A equipe de gestão precisa atuar cooperativamente e assumir a função de potencializar cada uma das competências apresentadas pelos professores-autores e designers de mediação.

Como resultado da investigação sobre a performance de professores-autores e designers de mediação numa equipe multidisciplinar de elaboração de materiais para um curso de licenciatura a distância se desenvolveu o Perfo_List. É um formulário no modo checklist composto por oito temas e cento e trinta e oito indicadores. Configura-se como uma ferramenta metodológica que auxilia os responsáveis pela gestão das equipes de produção nas instâncias da organização e otimização das ações implicadas na elaboração de materiais didáticos.

A investigação sobre a performance de professores-autores e designers de mediação numa equipe multidisciplinar gerou como resultado investigativo concreto esse guia apresentado no Quadro 1. Esse formulário pode orientar as ações dos gestores de equipes multidisciplinares de desenvolvimento de materiais didáticos para $\mathrm{EaD}$ tornando-se uma importante ferramenta de diagnósticos e replanejamentos. Pode ser utilizado pelos gestores em circunstâncias semelhantes resguardando-se adaptações em virtude das especificidades contextuais e administrativas. Existem especificidades dentro das equipes de elaboração de materiais que os gestores precisam conhecer e sobre as quais precisam tomar decisões, inclusive, imediatas. Por isso, o Perfo_List pode contribuir especialmente na organização das equipes de formação e capacitação enquanto ação estratégica no processo de gestão. A equipe de gestão precisa estar envolvida na produção do curso, na instituição, orientar as atividades pelos princípios pedagógicos e curriculares contemplados no projeto e ter conhecimento das competências, da autonomia e do comprometimento ético dos profissionais da equipe. As experiências bem sucedidas devem ser aproveitadas em ações prospectivas.

O Perfo_List é uma ferramenta metodológica desdobrada em Temas e Indicadores que servem de roteiros na elaboração de diagnósticos constantes sobre os encaminhamentos, fluxos de trabalhos, entendimentos, motivações e satisfações dos envolvidos. O Perfo_List auxilia na sistematização de diagnósticos sobre as ações dos professores-autores e designers de mediação em equipes multidisciplinares favorecendo a gestão desse processo.

\begin{tabular}{|l|l|l|}
\hline Temas & Indicadores \\
\hline $1 \quad$ Envolvimento na & a) Motivação; b) Satisfação; c) Tranqüilidade; d) \\
$\begin{array}{l}\text { Equipe Multidisciplinar } \\
\text { Sistema de relações }\end{array}$ & Segurança; e) Desafio; f) Conforto; g) Comprometimento \\
\hline $2 \quad$ Performance dos & a) Redação dos textos; b) Disponibilidade ao diálogo e \\
\hline
\end{tabular}




\begin{tabular}{|c|c|}
\hline $\begin{array}{l}\text { integrantes em relação } \\
\text { ao trabalho na equipe } \\
\text { multidisciplinar } \\
\text { Diversidade de perfis } \\
\text { profissionais }\end{array}$ & $\begin{array}{l}\text { resolução de problemas; c) Adequação dos conhecimentos } \\
\text { didático-metodológicos dos integrantes da equipe para as } \\
\text { respectivas funções; d) Competência na função; e) } \\
\text { Utilização de novas metodologias e procedimentos; f) } \\
\text { Utilização de tecnologias; g) Relacionamento com os } \\
\text { colegas; h) Cumprimento dos prazos previstos; i) } \\
\text { Cooperação; j) Autonomia na realização das atividades; k) } \\
\text { Esforço pessoal para melhoria das condições de trabalho e } \\
\text { dos resultados; l) Respeito e valorização das contribuições } \\
\text { dos colegas de equipe; m) Adequação dos conhecimentos e } \\
\text { competências em relação à EaD; n) Preparo para } \\
\text { mobilidade entre funções }\end{array}$ \\
\hline $\begin{array}{l}3 \text { Performance dos } \\
\text { integrantes nas } \\
\text { diferentes etapas de } \\
\text { elaboração dos } \\
\text { Diversas situações de } \\
\text { ensino-aprendizagem - } \\
\text { resultado da } \\
\text { composição da equipe } \\
\text { mediadores didáticos }\end{array}$ & $\begin{array}{l}\text { a) Priorização de conteúdos; b) Escrita dos conteúdos numa } \\
\text { linguagem dialógica; c) Organização didática dos } \\
\text { conteúdos; d) Organização temporal dos conteúdos; e) } \\
\text { Adequação dos conteúdos aos objetivos; f) Elaboração dos } \\
\text { objetivos; g) Redação de apresentações; h) Elaboração de } \\
\text { comentários de motivação; i) Indicação de links - } \\
\text { hipertextos; j) Elaboração de glossários, sínteses e resumos; } \\
\text { k) Criação de ilustrações, quadros, tabelas, gráficos, } \\
\text { esquemas; l) Orientação de atividades em grupo; m) } \\
\text { Elaboração de estudos de caso; n) Disponibilização de } \\
\text { exemplos e práticas; o) Elaboração de atividades de auto- } \\
\text { avaliação; p) Elaboração de atividades da prática como } \\
\text { componente curricular; q) Redação de comentários de } \\
\text { feedback; r) Preparação das videeoconferências; s) Indicação } \\
\text { de materiais complementares; t) Definição de critérios de } \\
\text { avaliação; u) Formulação de questões para as provas; v) } \\
\text { Preparo das atividades de interação síncrona para o AVEA; } \\
\text { x) Preparo das atividades de interação assíncrona para o } \\
\text { AVEA; z) Adequação da metodologia com as } \\
\text { especificidades da EaD; y) Adequação da organização dos } \\
\text { conteúdos às especificidades da EaD; w) Elaboração do } \\
\text { Plano de Ensino; } \alpha \text { ) Organização de diferentes situações de } \\
\text { ensino-aprendizagem }\end{array}$ \\
\hline $\begin{array}{l}4 \text { Designer de Mediação } \\
\text { Interfacer entre } \\
\text { concepção pedagógica, } \\
\text { metodologia e recursos }\end{array}$ & $\begin{array}{l}\text { a) Interferência na redação do texto; b) Diálogo- } \\
\text { problematizador com o professor-autor; c) Recomendações } \\
\text { didático-metodológicas; d) Adequação da formação inicial e } \\
\text { continuada; e) Competência em pedagogia e tecnologia; f) } \\
\text { Cooperação; g) Proposição de atividades de ensino- } \\
\text { aprendizagem; h) Sugestões de inserção de links, glossários, } \\
\text { ilustrações, resumos, animações, simulações, fóruns, lições, } \\
\text { hipertextos, vídeos...; i) Organização de conteúdo; j) } \\
\text { Sugestões de layout; k) Iniciativa para resolução de } \\
\text { problemas; l) Conhecimentos e competências em relação ao } \\
\text { conteúdo do curso; m) Conhecimento da documentação } \\
\text { relativa ao projeto, guias e legislação; n) Conhecimento em } \\
\text { EaD; o) Experiência em EaD; p) Experiência em elaboração } \\
\text { de material didático }\end{array}$ \\
\hline Condições & a) Adequação das definições do Projeto Pedagógico; b) \\
\hline
\end{tabular}




\begin{tabular}{|c|c|}
\hline $\begin{array}{l}\text { elaboração dos } \\
\text { mediadores didáticos } \\
\text { Condições requeridas }\end{array}$ & $\begin{array}{l}\text { Adequação das definições no Guia de Produção de } \\
\text { Materiais do Curso; c) Organização curricular; e) Co- } \\
\text { autoria; f) Adequação do tempo de trabalho para realizar as } \\
\text { atividades desejadas; g) Espaço físico; h) Laboratórios de } \\
\text { produção gráfica; i) Laboratórios de produção de vídeo; j) } \\
\text { Laboratórios de videoconferência; k) Ferramentas do } \\
\text { AVEA; l) Produção editorial; m) Comissão científica; n) } \\
\text { Comunicação na equipe multidisciplinar; o) } \\
\text { Compartilhamento das informações; p) Comunicação com a } \\
\text { Equipe de suporte ao AVEA; q) Diálogo entre Professor- } \\
\text { autor e Designer de Mediação; r) Revisão de língua } \\
\text { portuguesa; s) Infra-estrutura dos pólos; t) Diagnóstico do } \\
\text { público-alvo; u) Resultados de avaliação da Equipe de } \\
\text { Pesquisa e Avaliação; v) Programa de Capacitação de } \\
\text { Professores; x) Programa de Capacitação de Tutores; z) } \\
\text { Financiamento do Projeto. }\end{array}$ \\
\hline $\begin{array}{l}6 \text { Materiais de subsídio } \\
\text { para elaboração dos } \\
\text { mediadores didáticos } \\
\text { Práticas e materiais de } \\
\text { referência }\end{array}$ & $\begin{array}{l}\text { a) Livros de divulgação científica; b) Livros didáticos; c) } \\
\text { Periódicos, jornais, revistas; d) Teses e dissertações; e) } \\
\text { Livros e artigos de divulgação científica de autoria própria; } \\
\text { f) Materiais didáticos de própria autoria; g) Planejamentos } \\
\text { de aula já implementados na modalidade presencial; h) } \\
\text { Resultados de projetos de pesquisa da instituição; i) } \\
\text { Animações, simulações utilizadas pela comunidade } \\
\text { científica da área; j) Materiais didáticos para cursos a } \\
\text { distância elaborados por outras instituições; l) Textos de } \\
\text { eventos. }\end{array}$ \\
\hline $\begin{array}{l}7 \quad \text { Perfomance das } \\
\text { coordenações } \\
\text { Gestão do processo }\end{array}$ & $\begin{array}{l}\text { a) Envolvimento da coordenação do projeto; b) } \\
\text { Envolvimento da coordenação pedagógica; } \\
\text { Envolvimento da coordenação de AVEA; d) Metas de } \\
\text { desenvolvimento profissional; e) Compartilhamento de } \\
\text { idéias, objetivos, informações, soluções e resultados; f) } \\
\text { Preocupação com a manutenção do bom relacionamento } \\
\text { entre todos; g) Planejamento e capacitação; h) } \\
\text { Disponibilidade imediata para resolução dos problemas } \\
\text { urgentes; i) Entusiasmo e interesse na função; j) Adequação } \\
\text { do tempo de trabalho para realização das atividades } \\
\text { desejadas; k) Cumprimento dos prazos previstos; l) } \\
\text { Adequação das condições de infra-estrutura e apoio para } \\
\text { realização das atividades; m) Competências e habilidades } \\
\text { para o planejamento- prazos, recursos e ações; n) } \\
\text { Competências e habilidades na administração dos conflitos } \\
\text { e divergências; o) Definição de papéis e responsabilidades; } \\
\text { p) Planejamento de novos projetos }\end{array}$ \\
\hline \begin{tabular}{|lr}
8 & Potencialidade das \\
atividades & planejadas \\
nos & mediadores \\
didáticos & \\
Qualidade do processo
\end{tabular} & $\begin{array}{l}\text { a) Fóruns; b) Tarefas; c) Lições; d) Sala de discussões; e) } \\
\text { Webteca; f) Mural de avisos; g) Objetos de ensino- } \\
\text { aprendizagem, animações e simulações; h) Vídeos, som, } \\
\text { imagens; i) Glossários; j) Links internos e externos; k) } \\
\text { Hiperxtextos; 1) Atividades em grupos; m) Wikis; n) } \\
\text { Diários; o) Registros de observações; p) Prática como } \\
\text { componente curricular; q) Pesquisas bibliográficas; r) }\end{array}$ \\
\hline
\end{tabular}




\begin{tabular}{|l|l|}
\hline & $\begin{array}{l}\text { Experimentos de laboratório; s) Observações na } \\
\text { comunidade; t) Visitas temáticas; u) Resenhas, sínteses e } \\
\text { resumos; v) Preparação para videoconferências; x) Listas de } \\
\text { exercícios; z) Seminários; y) Relatórios }\end{array}$ \\
\hline
\end{tabular}

Quadro 1 - Perfo_List: metodologia para ações retrospectivas e prospectivas em equipes multidisciplinares

Fonte: Mallmann (2008).

\section{Ações retrospectivas e prospectivas na elaboração de materiais didáticos para EaD}

Compreender o trabalho numa equipe multidisciplinar de elaboração de materiais didáticos para $\mathrm{EaD}$ implica no movimento retrospectivo de registro e análise das ações já implementadas. Ao mesmo tempo, o componente prospectivo se apresenta na possibilidade de utilizar as informações apresentadas para planejar ações futuras tais como: a) reorganizar equipes; b) rever conceitos; c) investir em capacitações específicas; d) especificar funções; e) priorizar a clareza no fluxo de informações; f) sustentar princípios como a autonomia, interação e cooperação no interior da equipe; g) atender demandas formativas específicas e emergenciais; h) contextualizar a inovação na docência universitária explicitando as potencialidades científicas, didáticas, políticas, éticas e investigativas da autoria e co-autoria dos materiais didáticos; i) ampliar a riqueza da inserção dos mediadores tecnológicos como objetos e ambientes virtuais de ensino-aprendizagem na modalidade a distância.

O Perfo_List pode-se alimentar a organização de informações sobre os profissionais, os eventos e lugares em que as ações de elaboração de materiais didáticos acontecem. Para isso, é necessário problematizar o processo e tomar decisões balizadas pelos princípios da competência, autonomia, cooperação e ação ética no trabalho em equipes multidisciplinares. A compreensão sobre a performance docente pode gerar ciclos compostos de etapas de planejamento, desenvolvimento, reflexão e avaliação evidenciando proposições e ações concretas para resolver os problemas mais urgentes e atender as demandas dos projetos em desenvolvimento na modalidade a distância. O Perfo_List demonstra a complexidade das questões teórico-metodológicas envolvidas num processo de elaboração de materiais didáticos para EaD. Os temas e indicadores contemplados nesse formulário podem, eventualmente, ser reorganizados em decorrência de especificidades conceituais das áreas de conhecimentos, condições logísticas requeridas e perfil da população envolvida.

O Perfo_List é uma proposição metodológica que pode subsidiar a compreensão das rotinas de produção de materiais didáticos em equipes multidisciplinares de modo que as singularidades possam ser mapeadas com mais precisão. Cada equipe tem suas especificidades em virtude da competência, autonomia e condições de ação de cada um dos envolvidos.

Em EaD se faz necessário planejar e antecipar escolhas que possam potencializar a mediação pedagógica em congruência com os projetos pedagógicos dos cursos. Por isso, a sistematização, organização e construção desse formulário de indicadores, para sustentar o movimento retrospectivo e prospectivo na elaboração de materiais didáticos para $\mathrm{EaD}$, levou em consideração princípios e critérios de pesquisa que geraram registros e resultados utilizados como referência na proposição. No mesmo lastro, contempla resultados de pesquisas divulgados no cenário nacional e internacional cujos indicadores alertam para especificidades da modalidade a distância como, por exemplo, 
envolvimento de diversos profissionais nas equipes multidisciplinares, atribuições do designer de mediação, modelos pedagógicos, gestão de infra-estrutura, desenvolvimento de novos métodos e tecnologias, potencialidades síncronas e assíncronas das tecnologias.

O Perfo_List é resultado de uma investigação no contexto real e específico de uma equipe multidisciplinar envolvida na elaboração de materiais impressos e hipermidiáticos para atender a demanda de um curso de licenciatura. Ao longo do percurso a necessidade de organizar melhor as condições dialógicas, interativas e cooperativas da equipe foi se tornando explícita. A preocupação no momento de desenvolvimento do Perfo_List levou em consideração conceitos de gestão e performance docente ancorados nos princípios da comunicação, comprometimento ético, competência docente, interação, cooperação e autonomia. O Perfo_List é uma proposição possível de ser redesdobrada conforme necessidades emergenciais em diferentes instituições. Nessa perspectiva, se situa o propósito de dar continuidade ao seu desenvolvimento dando-lhe um formato eletrônico.

Sabe-se de empecilhos que podem ser motivados pela necessidade de atender demandas contingenciais acarretando restrições temporais ou formativas dos profissionais envolvidos. A validade e ineditismo da proposição do Perfo_List se situa especialmente como iniciativa que pode contribuir na organização dos processos produtivos no interior das equipes multidisciplinares que envolvem a cada dia mais profissionais em virtude da expansão da própria modalidade. O Perfo_List pode servir de indicativo para investimento em investigações, rigor e profundidade nos estudos sobre as preocupações em torno das questões teórico-metodológicas da mediação pedagógica em EaD concentradas no processo de elaboração de materiais didáticos para $\mathrm{EaD}$, organização e gestão de equipes multidisciplinares e utilização de tecnologias digitais de informação e comunicação em $\mathrm{EaD}$.

\section{Referências Bibliográficas}

FILATRO, A. Design instrucional contextualizado: educação e tecnologia. São Paulo: Editora Senac, 2004.

ISMAN, Aytekin et al. A new model for the world of instructional design: a new model. The Turkish Online Journal of Educational Technology -TOJE, vol 4, 2005. Disponível em: $<$ http://www.eric.ed.gov/ERICWebPortal/contentdelivery/servlet/ERICServlet?accno=E D484983>. Acesso em: 10 agosto 2007.

JUUTI, Kalle. Towards primary school physics teaching and learning: desing reseach approach. Faculty of Behavioral Sciences/ University of Helsinski, 2005. Doctoral Dissertation.. Disponível em: <http://www.eric.ed.gov/ERICWebPortal/contentdelivery/servlet/ERICServlet?accno=E $\underline{\mathrm{D} 489993}$ >. Acesso em: 08 agosto de 2007.

LATOUR, Bruno. A vida em Laboratório. São Paulo: Relumé-Dumará, 1999.

LATOUR, Bruno. A Esperança de Pandora: ensaios sobre a realidade dos estudos ientíficos. Bauru, SP: EDUSC, 2001.

MALLMANN, Elena Maria. Mediação pedagógica em educação a distância: cartografia da performance docente no processo de elaboração de materiais didáticos. Florianópolis: UFSC/PPGE, 2008. 304p. Tese de doutorado. 
MALLMANN, Elena. M. e CATAPAN, Araci. H. Materiais didáticos em educação a distância: gestão e mediação pedagógica. Revista Linhas, Florianópolis, v.8, nº2, jul/dez, 2007.

ROMISZOWSKI, Alexander e ROMISZOWSKI, Lina. Retrospectiva e Perspectivas do Design Instrucional e Educação a Distância: análise da literatura. Revista Brasileira de Aprendizagem Aberta e a Distância. v. 3, $\mathrm{n}^{\mathrm{o}}$ 1, 2005. Disponível em: <http://www.abed.org.br>. Acesso em: 03 maio 2008.

RUMBLE, Greville. A gestão dos sistemas de ensino a distância. Brasília: UNB; UNESCO, 2003.

VARGAS, Johanna M. Etapas el desarrollo y planteamientos actuales en la producción de los materiales impresos de la universidad estatal a distancia de costa rica (UNED). Revista Iberoamericana de Educación a Distancia (RIED), vol.10, nº 1, 2007. 